\title{
Discursos de orientadores brasileiros e franceses no e sobre o feedback aos textos de seus mestrandos e doutorandos: um olhar sobre critérios e expedientes em torno da apropriação da palavra de outrem na escrita acadêmica ${ }^{1}$
}

\author{
Juliana Alves Assis ${ }^{2}$ \\ Instituto de Ciências Humanas/Programa de Pós-graduação em Letras, Pontifícia Universidade Católica de \\ Minas Gerais (PUC Minas), Belo Horizonte, MG, Brasil
}

\begin{abstract}
Resumo: A inserção de estudantes no mundo social e discursivo das instituições de ensino superior pressupõe a significação, por parte desses novos membros, das normas sociais de uso da linguagem em práticas em que os gêneros acadêmicos são atualizados. Entre os conhecimentos necessários para essa inserção, recorto, neste trabalho, aqueles que se referem ao uso do discurso de outrem na escrita de textos acadêmicos em textos produzidos no âmbito do mestrado e do doutorado. De modo específico, busco examinar, em entrevistas e em intervenções feitas nos textos de mestrandos e doutorandos, as visões de professores franceses e brasileiros sobre como seus orientandos constroem, no texto, sua relação com a palavra de outrem.
\end{abstract}

Palavras-chave: Escrita acadêmica; Letramento; Feedback.

Title: Discourses by Brazilian and French advisors within and about the feedback to the texts of their master's and doctoral students: a look on the criteria and resources around the appropriation of other's words in academic writing

Abstract: The insertion of students in the social and discursive world of higher learning institutions presupposes the signification, by these new members, of the social norms for using language in practices in which academic genres are utilized. Among the skills necessary for this insertion, I highlight, in this work, those that regard the use of the discourse of others in the writing of academic texts in texts produced within the scope of master's and doctorate degrees. Specifically, I seek to examine, in interviews and interventions made in the texts of master's and doctoral students, the views of French and Brazilian professors about how the students they advise construct, in the text, their relationship with the words of others.

Keywords: Academic writing; Literacy; Feedback.

\footnotetext{
${ }^{1}$ Este texto abriga resultados parciais de pesquisa desenvolvida no âmbito do Projeto Capes/Cofecub 834/15 (2015-2018), intitulado "Discurso acadêmico na pesquisa e no ensino: questões em torno da apropriação da palavra de outrem" [Le discours universitaire dans la recherche et l'enseignement: questions autour de l'appropriation de la parole d'autrui]. A frente de pesquisa a que se vincula a pesquisa também recebe apoio do CNPq, considerado o projeto "A escrita acadêmica em uma perspectiva dialógica: ser e dizer com e a partir da palavra de outrem".

${ }^{2}$ Doutora em Estudos Linguísticos (UFMG), professora da PUC Minas. Bolsista de Produtividade em Pesquisa do CNPq. Orcid: http://orcid.org/0000-0002-9383-4850

E-mail: juassis@terra.com.br
} 


\section{Primeiras palavras sobre a escrita acadêmica: em torno dos desafios}

"Eu chego a pensar que escrever é algo que dói na gente." Proferido por um estudante de graduação em Letras numa roda de discussão sobre a escrita acadêmica ${ }^{3}$, o enunciado que abre este texto remete a um conjunto de obstáculos aos quais costuma ser associada a prática da escrita acadêmica, percepção que não se limita aos estudantes recém-ingressos na educação superior, estendendo-se a mestrandos, doutorandos e mesmo pesquisadores mais experientes.

Tais obstáculos, materializados na ideia de dor que emerge no enunciado posto em destaque, poderiam ser descritos por meio de distintos matizes, dentre os quais a insegurança com relação ao que escrever, a dificuldade de encontrar a forma adequada para a escrita (o "tom" do texto), a pressão de prazo para o desfecho do texto a ser escrito (ou seja, a não coincidência entre o tempo do processo de escrita e o tempo estabelecido para apresentação de seu produto), apenas para mencionar alguns dos entraves frequentemente aludidos por alunos e professores universitários.

Tendo em conta o percurso de inserção do estudante no ensino superior, desde a graduação até o doutorado, e ainda na esteira das chamadas dificuldades por este vividas, tomo para reflexão neste texto aquelas que dizem respeito à apropriação do discurso de outrem na escrita acadêmica. Atrelada à necessidade de ancoragem teórica no texto acadêmico, a apropriação do discurso de outrem impõe também ao estudante a construção de uma voz autoral que - idealmente - seja capaz de endossar, discordar, refletir, discutir e argumentar em meio à tensa e dialética relação com as vozes convocadas. Mais especificamente, interessa-me tratar essa questão a partir da perspectiva do professor de pósgraduação, orientador de teses e dissertações, considerado o seu papel no processo de letramento vivido pelo estudante (cf. STREET, 1984, 2003; LEA; STREET, 2014; KLEIMAN; ASSIS, 2016, dentre outros). Esse interesse se traduz no objetivo de examinar, em entrevistas concedidas à pesquisadora e em intervenções feitas em textos de mestrandos e doutorandos, as visões de professores franceses e brasileiros sobre como tais estudantes constroem, no texto, sua relação com a palavra de outrem.

Para além destas palavras introdutórias, este texto abriga uma discussão sobre a perspectiva a partir da qual se toma o discurso de outrem na escrita acadêmica, seguida de reflexão sobre o papel do feedback escrito do professor aos textos de mestrandos e

\footnotetext{
${ }^{3}$ Trata-se de um grupo de discussão sobre a escrita acadêmica envolvendo 8 estudantes da graduação em Letras, em 2010, todos eles com experiência em projeto de iniciação científica. Esse expediente gerou conversa em torno das práticas de escrita na universidade, que foi gravada e posteriormente transcrita.
} 
doutorandos no processo de letramento acadêmico. Após isso, são apresentados os dados da pesquisa, aos quais se seguem a análise e breves considerações a título de fecho do texto.

\section{Relações com a palavra de outrem na escrita acadêmica: algo para além da prescrição técnica}

A compreensão dos diferentes parâmetros que regem o uso da palavra de outrem no discurso científico está longe de ser alcançada tão somente pelo cumprimento de parâmetros de normalização, tais como os que emanam da Associação Brasileira de Normas Técnicas (ABNT), no caso do Brasil, ou de qualquer outra norma técnica. ${ }^{4}$

Isso se explica pelo fato de que ações como citar um autor, parafraseando ou transcrevendo suas ideias, aludir a um conceito cunhado por outrem ou a uma determinada corrente teórica ou domínio epistemológico, a despeito de serem disciplinadas pelas mencionadas normas, são, antes de mais nada, expedientes por meio dos quais o escrevente constrói seu "corpo" no texto, evidenciando sua estatura intelectual e revelando, por isso, seu lugar na comunidade discursiva (cf. MAINGUENAU, 1993) em que esse texto é gerado. Há, nessa medida, efeitos não necessariamente controlados ou intencionados pelo escrevente quando este recorre ao discurso de outrem na composição do texto acadêmico.

Nessa mesma direção, Boch e Grossmann (2015, p. 284) assinalam que "citar o outro é [...] aceitar entrar em uma série de jogos particulares, que vão interferir na enunciação do autor". Três são os jogos enumerados pelos autores, os quais interessam à discussão proposta neste artigo:

Jogo de posições: a voz de um autor citado representa uma posição argumentativa em relação à qual o produtor do texto se situa pragmaticamente (acordo versus desacordo) com todas as variantes intermediárias. Jogo de lugares: a autoridade que funda o discurso citado e o modo pelo qual se efetiva sua legitimação pelo produtor do texto não é dada. Com efeito, citar implica construir essa autoridade, não apenas escolhendo sabiamente os autores a serem citados, mas também aprendendo a integrá-los aos campos nos quais eles se inscrevem e em relação ao sistema de normas ao qual se referem. Jogo de faces: como em qualquer diálogo, colocam-se, inevitavelmente, problemas de segurança/insegurança, dominação/submissão, relacionados com a discrepância entre a posição de autores iniciantes relativamente aos que se thes apresentam como especialistas. Assim, longe de ser uma prática inofensiva ou apenas decorativa, a citação faz emergir problemas fundamentais. Ela

\footnotetext{
${ }^{4}$ Tais normas frequentemente representam desafios não apenas para os alunos de graduação, mestrado e doutorado, mas também para grande parte de membros experts da comunidade acadêmica, o que explica inclusive a atuação de profissionais de revisão especializados nessas normas trabalhando para periódicos de alto impacto.
} 
exibe ou, inversamente, mascara as estratégias dos sujeitos: eliminação total ou parcial diante (ou melhor, atrás) do discurso do outro, posição de superposição crítica, de distância ou de avaliação, recuo prudente diante de uma afirmação que não se ousa endossar etc. (BOCH; GROSSMANN, 2015, p. 284-285.)

Essa complexidade de papéis e efeitos (calculados ou não) do discurso citado no discurso citante, tal como abordada pelos dois pesquisadores franceses, ampara a defesa de que a orquestração de vozes na escrita acadêmica seja vivida e significada pelo estudante de ensino superior não exclusivamente a partir de uma técnica (como insistem muitos manuais dedicados a fornecer uma modelização para esse tipo de escrita), mas, sim, fundamentalmente, como modos de agir do escrevente em relação tanto ao que ele próprio enuncia quanto ao que enuncia o autor que ele convoca para seu texto e com quem dialoga. Há, nesse trabalho dialógico, uma atitude responsiva, aqui assumida na perspectiva bakhtiniana (BAKHTIN, 2003), também frente às expectativas da comunidade acadêmica de que o estudante passa a fazer parte.

A significação da escrita acadêmica pelo estudante universitário, nos termos até então expostos, emerge exatamente de sua experiência nas instituições de ensino superior. Noutros termos, as práticas discursivas que têm lugar nessas instituições - aulas, seminários, debates, congressos, etc. - funcionam como meios para significação, pelo estudante, dessas próprias práticas bem como dos valores, crenças, saberes e gêneros nelas mobilizados, tal como nos lembra Hyland (2012). Ao longo desse percurso, os estudantes "lentamente assumem os discursos e entendimentos dessa disciplina para construir um self que ganha reconhecimento e reforço por meio do uso desses mesmos discursos" (HYLAND, 2012, p. 3, tradução minha). ${ }^{5}$

Há aí, portanto, instaurado um processo de socialização, marcadamente dialógico, com todas as tensões que isso pode pressupor, e que é orientado pelas expectativas e parâmetros dessa nova comunidade discursiva na qual o estudante adentra e que passa a integrar.

Dentre as diferentes práticas discursivas que têm lugar no processo de formação no ensino superior, interessa de modo particular aos propósitos deste trabalho o feedback escrito dos professores acerca dos textos produzidos por seus estudantes, exatamente por ele se caracterizar como uma intervenção direta e personalizada, dirigida ao autor do texto e, dessa forma, agir responsivamente tanto em relação ao projeto de dizer do escrevente como ao processo de letramento acadêmico em curso. Assim, a forma como o professor interage com os textos produzidos por seus estudantes, tendo em conta os expedientes e critérios de correção/avaliação/apreciação por ele adotados, traz a memória do modo como ele entende seu papel no processo de letramento acadêmico em curso, bem como revela representações

\footnotetext{
5 "[...] slowly take on its discourses and understandings to construct a self which gains recognition and reinforcement through use of these discourses."
} 
implicadas na ação docente, seja em relação aos objetos de conhecimento em foco, seja em relação ao estudante, seja ainda em relação à própria prática de escrita acadêmica.

\section{Sobre a prática de avaliação/apreciação de textos no processo de letramento acadêmico}

Seja qual for o nível de atuação e a área do professor, é preciso considerar que a avaliação integra o elenco das atividades que caracterizam o seu fazer profissional. Nessa medida, as práticas de ensino/aprendizagem sempre envolvem algum tipo de ação avaliativa/apreciativa por parte do professor.

No sentido preconizado por este texto, a avaliação é tomada, sobretudo, como ação que visa a diagnosticar uma experiência, de forma a poder reorientá-la na direção do melhor desenvolvimento possível; nessa medida, desvincula-se de uma perspectiva classificatória ou seletiva (LUCKESI, 2002). ${ }^{6}$

Relativamente ao processo de apropriação de gêneros do discurso por parte dos estudantes, as ações de avaliação/apreciação efetivadas pelo professor, em feedback escrito ou oral, assumem papel valioso, uma vez que podem apoiar o estudante (i) na construção de conhecimentos relativos à configuração e ao funcionamento dos textos; (ii) no desenvolvimento de habilidades necessárias à textualização e, por consequência; (iii) no desenvolvimento de sua capacidade de reflexão sistemática sobre a língua e a linguagem (ASSIS, 2016).

É sob essas condições que os comentários escritos pelo professor de ensino superior nos (ou sobre os) textos produzidos por seus orientandos ao longo do mestrado e do doutorado são, neste trabalho, tomados como imprescindíveis ao processo de letramento acadêmico. Sob esse ponto de vista, à ação de avaliação de textos acadêmicos por parte do professor subjazem saberes e valores caros ao discurso científico e ao campo disciplinar específico, os quais vão sendo, paulatinamente, reconhecidos e apropriados/mobilizados pelos estudantes em seus novos textos, tomados como ação responsiva aos feedbacks

\footnotetext{
${ }^{6}$ Conforme descreve Romão (2002), em diálogo com Luckesi (2002), há, pelo menos, duas orientações distintas para a avaliação: [...] "a avaliação tem sido mais frequentemente usada como instrumento da meritocracia, da discriminação e, no limite, da exclusão Neste caso, ela funciona como julgamento, desembocando em veredictos sobre o desempenho humano. Na sua versão diagnóstica, ela se volta para o levantamento de dificuldades em determinado desempenho humano, buscando sua superação, pois, aí sim, visa à inclusão do agente no universo dos que lograram êxito no mesmo desempenho. Na versão julgadora ou classificatória, identifica acertos e erros para premiar ou punir seus respectivos agentes, confirmando sua teleologia excludente em relação aos últimos. Em suma, a avaliação pode funcionar como diagnóstico ou como exame; como pesquisa ou como classificação; como instrumento de inclusão ou de exclusão; como canal de ascensão ou critério de discriminação" (ROMÃO, 2002, p. 44).
} 
recebidos. Da mesma forma, como já assinalado, a avaliação de textos pelo professor é vista como a manifestação de sua compreensão responsiva ativa ao projeto de dizer do aluno, construído na rede dialógica que todo e qualquer texto pressupõe.

\section{Visão geral dos dados da pesquisa}

A análise a ser apresentada focalizará parte de corpus franco-brasileiro constituído ao longo de 2015 e 2016. Trata-se de (i) entrevistas gravadas com 7 professores de IES ${ }^{7}$ brasileiras e 10 professores de IES francesas, ${ }^{8}$ em um total de 7 h10 de gravação transcritas, (ii) e de textos produzidos por estudantes de universidades brasileiras e francesas, todos com intervenções dos professores entrevistados e por eles cedidos à pesquisa.

Os quadros a seguir apresentam informações acerca desses colaboradores, tendo em vista sua experiência profissional no ensino superior.

\begin{tabular}{|l|l|l|l|}
\hline Professor & $\begin{array}{l}\text { Quadro 1 - Visão geral dos professores colaboradores do Brasil } \\
\text { ensino superior }\end{array}$ & $\begin{array}{l}\text { No de orientações de } \\
\text { dissertações concluídas }\end{array}$ & $\begin{array}{l}\text { No de orientações de } \\
\text { teses concluídas }\end{array}$ \\
\hline PB $^{10} \mathbf{1}$ & 26 anos & 16 & 5 \\
\hline PB2 & 29 anos & 13 & 9 \\
\hline PB3 & 16 anos & 7 & 1 \\
\hline PB4 & 13 anos & 5 & 0 (2 em andamento) \\
\hline PB5 & 15 anos & $0(2$ em andamento) & 0 \\
\hline PB6 & 25 anos & 13 & 6 \\
\hline PB7 & 32 anos & 20 & 13 \\
\hline
\end{tabular}

Fonte: Dados da pesquisa.

Os sete professores se distribuem em 3 IES distintas. Todos possuem publicações nacionais e internacionais na área de Letras, com experiência de pesquisa em temas como formação de professores, gêneros do discurso, escrita universitária, leitura, etc. Além disso, todos atuam nos três níveis de formação universitária - graduação, mestrado e doutorado -,

\footnotetext{
7 IES (Instituição de ensino superior).

${ }^{8}$ Foi realizada e gravada uma 11 a entrevista na França, porém, em razão de problemas técnicos, ela não pôde ser transcrita. Já os textos cedidos por esse 11으 professor integram o corpus da pesquisa, conforme Quadro 4.

${ }^{9}$ Informações de 2016.

${ }^{10}$ PB (professor de IES brasileira).
} 
4 deles ministrando, na graduação, disciplinas dedicadas especificamente ao ensino da escrita e da leitura na universidade. ${ }^{11}$

Vejamos a seguir informações acerca dos professores de IES francesas.

Quadro 2 - Visão geral dos professores colaboradores da França ${ }^{12}$

\begin{tabular}{|l|l|l|l|}
\hline Professor & $\begin{array}{l}\text { Tempo de atuação no } \\
\text { ensino superior }\end{array}$ & $\begin{array}{l}\text { Orientações de master } \\
\text { concluídas }\end{array}$ & $\begin{array}{l}\text { Orientações de teses } \\
\text { concluídas }\end{array}$ \\
\hline PF $^{\mathbf{1 3}} \mathbf{1}$ & 15 & 60 & 3 \\
\hline PF2 & 25 & 75 & 0 (2 em andamento) \\
\hline PF3 & 21 & 40 & 4 \\
\hline PF4 & 22 & 80 & 4 \\
\hline PF5 & 25 & 150 & 2 \\
\hline PF6 & 22 & 60 & 0 \\
\hline PF7 & 35 & 170 & 5 \\
\hline PF8 & 25 & 60 & 10 \\
\hline PF9 & 23 & 100 & 0 \\
\hline PF10 & 22 & -14 & -15 \\
\hline & & & \\
\hline
\end{tabular}

Fonte: Dados da pesquisa.

Os 10 professores indicados no Quadro 2 se distribuem em 3 IES francesas. Tal como os professores das IES brasileiras, todos possuem publicações nacionais e internacionais na área de Letras, com experiência de pesquisa em temas que variam entre didática de língua materna e de língua estrangeira, semântica lexical, escrita universitária, etc. Igualmente, todos atuam nos três níveis de formação universitária - graduação, mestrado e doutorado - 2 deles ministrando cursos dedicados especificamente ao ensino da escrita acadêmica na graduação e no mestrado. ${ }^{16}$

Nos Quadros 3 e 4, a seguir, são trazidas informações sobre os textos cedidos pelos professores de cada país, referentes aos níveis de mestrado e doutorado.

\footnotetext{
${ }^{11}$ Dados de 2016.

${ }^{12}$ Informações de 2015.

${ }^{13}$ PF (professor de IES francesa).

${ }^{14}$ PF10 afirmou na entrevista não ter exata noção do número de orientações de master e sugeriu que isso pudesse ser verificado em seu CV online. Entretanto, essa informação não foi encontrada na Web. ${ }^{15}$ Também com relação ao número de orientações de doutorado, PF10 afirmou na entrevista não ter exata noção e sugeriu que isso pudesse ser verificado em seu CV online. Essa informação, porém, não foi encontrada na Web.

${ }^{16}$ Dados de 2015.
} 
Quadro 3 - Textos com intervenção dos professores do Brasil

\begin{tabular}{|c|c|c|}
\hline Prof. & Mestrado & Doutorado \\
\hline PB1 & $\begin{array}{l}3 \text { capítulos de uma dissertação } \\
\text { (Letras - 2010) } \\
3 \text { capítulos de uma dissertação } \\
\text { (Letras - 2009) }\end{array}$ & 3 capítulos de uma tese (Letras - 2012 e 2013) \\
\hline PB2 & $\begin{array}{l}2 \text { capítulos de uma dissertação } \\
\text { (Letras - 2008) } \\
3 \text { capítulos de uma dissertação } \\
\text { (Letras - 2011) }\end{array}$ & 3 capítulos de uma tese (Letras - 2011 e 2012) \\
\hline PB3 & 1 dissertação completa (2014) & - \\
\hline PB4 & $\begin{array}{l}3 \text { capítulos de uma dissertação } \\
\text { (Letras - 2014-2015) }\end{array}$ & - \\
\hline PB5 & - & 2 capítulos de 2 teses (Letras - 2014 e 2015) \\
\hline PB6 & $\begin{array}{l}4 \text { capítulos de dissertação (Letras - } \\
2014 \text { e 2015) }\end{array}$ & - \\
\hline PB7 & $\begin{array}{l}4 \text { capítulos de dissertação (Letras - } \\
2013 \text { e 2014) }\end{array}$ & $\begin{array}{l}3 \text { capítulos de uma tese (Letras - } 2014 \text { e 2015) } \\
2 \text { capítulos de uma tese (Letras - 2015) }\end{array}$ \\
\hline
\end{tabular}

Fonte: Dados da pesquisa.

Quadro 3 - Textos com intervenção dos professores da França

\begin{tabular}{|c|c|c|}
\hline Prof. & Mestrado & Doutorado \\
\hline PF1 & - & - \\
\hline PF2 & - & - \\
\hline PF3 & $\begin{array}{l}5 \text { sínteses de pesquisa do master } 1 \\
\text { (Ciências da Linguagem) }\end{array}$ & 1 projeto de tese (Ciências da Educação) \\
\hline PF4 & - & - \\
\hline PF5 & $\begin{array}{l}11 \text { sínteses de pesquisa do master } 1 \\
\text { (Ciências da Linguagem - 2014-2015) } \\
4 \text { seções teóricas de mémoires de master } \\
2 \text { (Ciências da Linguagem - 2015) }\end{array}$ & $\begin{array}{l}5 \text { capítulos de tese (2013 e 2015) } \\
2 \text { artigos de doutorandos (2015) }\end{array}$ \\
\hline PF6 & - & - \\
\hline PF7 & $\begin{array}{l}1 \text { capítulo de mémoire (Didática e ensino } \\
\text { do Francês como Língua estrangeira - } \\
\text { 2015) }\end{array}$ & 1 capítulo de tese (2015) \\
\hline
\end{tabular}




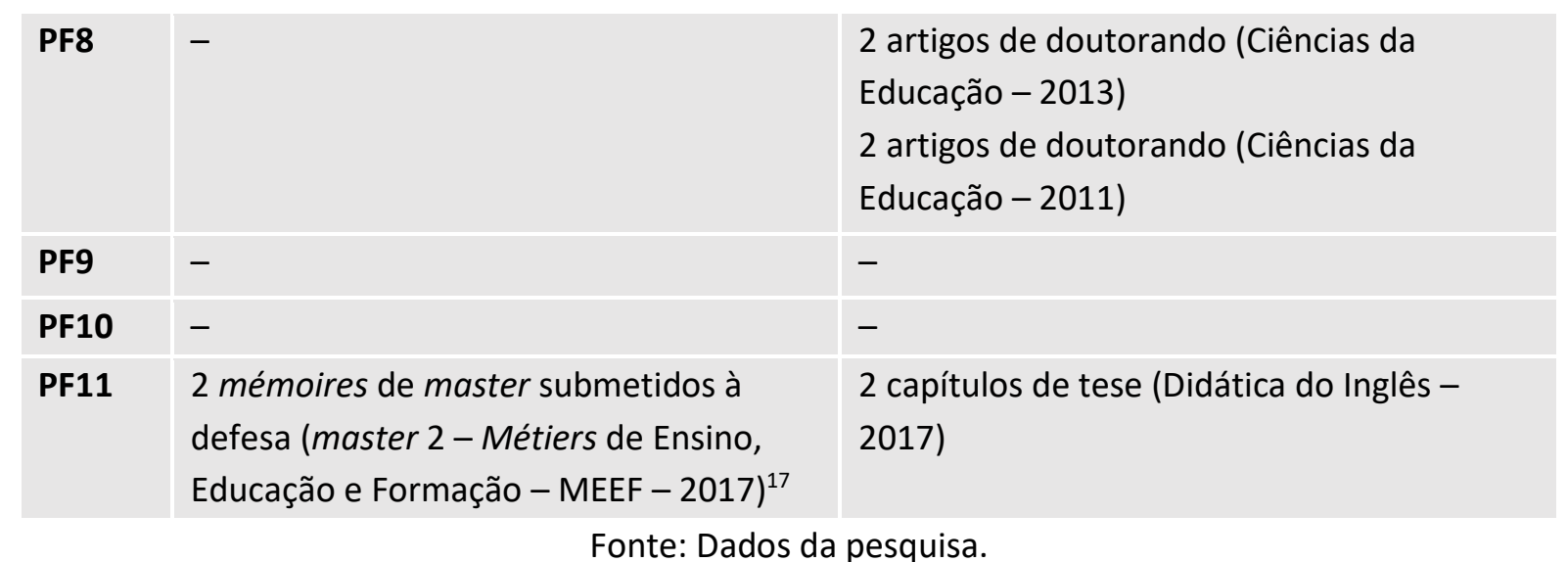

Fonte: Dados da pesquisa.

O conjunto desses textos perfaz cerca de 2.100 páginas, quase que inteiramente em arquivos eletrônicos, havendo apenas poucos textos em papel, compondo 56 páginas. Observe-se que a informação de data não foi fornecida para todos os textos.

A diferença no número de textos por professor se explica pelo caráter voluntário do processo de coleta de dados, como é de supor. É de notar ainda que os textos que integram esse corpus resultam de investimento em pesquisa por parte de pesquisadores debutantes (caso do mestrado, no Brasil, ou do master, na França) ou um pouco mais experientes, mas ainda não especialistas (caso do doutorado, com a tese ou com artigo escrito no percurso do doutorado).

Discursos no e sobre o feedback aos textos de mestrandos e doutorandos: a visão dos professores

Os professores universitários que colaboraram com a pesquisa são representados, neste texto, como seres do discurso, afetados pelo exterior (a comunidade universitária, a comunidade disciplinar, a comunidade científica, as normas para a mensuração da qualidade científica, as especificidades da situação de interação, etc.)

O trabalho toma para análise discursos desses professores em duas situações de interação distintas: em entrevista de pesquisa com a pesquisadora e no feedback aos mestrandos e doutorandos que orientam.

\footnotetext{
${ }^{17}$ As anotações do professor não se apresentaram no corpo do texto do estudante, como nos demais casos, e sim foram trazidas em folha à parte.
} 
Nos discursos dos professores entrevistados revelam-se pequenas tensões inerentes à tarefa de avaliação de textos na universidade, seus limites e papéis, bem como à própria imagem que o professor constrói de si e dos estudantes ao falar sobre ela. Apresento ao leitor, no quadro 4 , três excertos das entrevistas ${ }^{18}$ que nos permitem refletir sobre esse aspecto:

Quadro 4-Discurso dos professores nas entrevistas

1. [...] mestra::do é:: no doutorado eu NUNca corrijo MESMO... pode ser que a gente acabe de vez em quando... eu não POsso dizer também que na graduação eu não corrija[...] isso é algo que eu tenho até é/ é... até por uma questão de:: de criar mesmo uma certa independência/não que a graduação eu sinta que HAja mais depenDÊNcia... mas eu às vezes inDIco em amarelo e peço pra rever... é:: há uma paráfrase que:: eu/eu comento... é::... "a paráfrase reMEte a uma outra intepretação... a paráfrase não foi fiel... reveja... volte ao tex/ volte ao autor"... por isso que o eletrônico me dá muito mais condições porque eu tenho condição até de confrontar... (PB3)

2. às vezes eu reescrevo TREchos... enfim... acontece... né... você reescrever... mas QUANdo é uma... outra questão que eu julgo mais importante em relação ao gênero... em relação à imagem que ele tá construin::do... uma questão que NÃO É de MEra sinTAxe... apesar de a sintaxe também tá a favor... né... as reesCRItas... eu fa/eu mesma faço a reescrlta... (PB5)

3. mais pour des étudiants qui n'ont pas forcément un problème de langue, je préfère effectivement pas donner les solutions toutes faites mais les faire chercher... leur donner des pistes... (PF10)

\section{Fonte: Dados da pesquisa.}

É importante assinalar, de início, que o exame dos discursos dos professores em situação de entrevista não permite apontar propriamente um consenso acerca do que é tomado por eles como problema mais ou menos grave nos textos que examinam, mas é bastante recorrente nos dados a ideia de que haveria uma relação estreita entre os expedientes de correção adotados pelo professor e seus efeitos na formação do estudante,

\footnotetext{
${ }_{18}$ Para as transcrições, utilizo as normas do Projeto NURC/SP (CASTILHO; PRETI, 1987, p. 9), conforme a seguir explicitado: (i) incompreensão de palavras ou segmentos: ( ); (ii) truncamento: /; (iii) entoação enfática: maiúsculas; (iv) alongamento de vogal: :: ou :::: ; (v) qualquer pausa: ... ; interrogação: ? ; (vi) voz imposta, para citações literais ou leitura de textos, recapitulação de palavras do interlocutor, etc.: " "; (vii) indicação de trecho omitido: /.../ ou [...] .
} 
por exemplo no que se refere à construção de uma "autonomia" na escrita. São, portanto, conflitos que se revelam fortemente com relação ao limite para a intervenção do professor no texto do aluno e quanto à sua natureza - resolutiva ${ }^{19}$ ou não, por exemplo -, aspecto relacionado também ao tipo de problema flagrado.

O nível de formação do autor do texto é outro fator presente nos discursos dos professores, também certamente por força de a entrevista ter tematizado, por vezes separadamente, a graduação, o mestrado e o doutorado. Há, como era previsível, a menção a uma espécie de gradação de expertise para a escrita acadêmica, relacionada ao nível de formação (mesTRA::do é:: no doutorado eu NUNca corrijo MESMO... pode ser que a gente acabe de vez em quando... eu não POsso dizer também que na graduação eu não corrija [...] isso é algo que eu tenho até él é... até por uma questão de:: de criar mesmo uma certa independência...).

Outro aspecto que me parece importante destacar, nos excertos ilustrados, são determinados conflitos subjacentes à prática de avaliação dos textos dos estudantes: (i) a ação de resolver o problema que o texto apresenta versus a ação de indicar pistas para que os estudantes encontrem por si mesmos a solução; (ii) o tipo de problema que o estudante

\footnotetext{
${ }^{19}$ Trata-se de correção caracterizada pela apresentação e solução dos problemas detectados nos textos, conforme tipologia apresentada por de Ruiz (2001). Recorro a trabalho anterior (ASSIS, 2016) para detalhar a tipologia referida bem como reiterar posicionamentos sobre ela, tendo em vista que estes se coadunam com a perspectiva adotada neste texto: “Apoiando-se em Serafini (1989) e tomando como objeto de análise a atividade de correção por professores da educação básica de textos produzidos por seus alunos em situação escolar, Ruiz (2001)descreve quatro tipos de correção [...]: a) a correção resolutiva, caracterizada pela apresentação e solução dos problemas detectados nos textos, ou seja, o professor marca e corrige o problema flagrado no texto do aluno (normalmente, esse tipo de correção é usado para tratar problemas formais do texto: ortografia, desvios de concordância, pontuação, etc.); b) a correção indicativa, caracterizada pela indicação local dos problemas encontrados nos textos, normalmente por meio de grifos, círculos ou outra forma de notação que apenas aponta para o aluno que existe algum problema no local marcado, mas sem especificação de sua natureza; c) a correção classificatória, por meio da qual a natureza dos problemas detectados é apontada, através de metalinguagem codificada específica (por exemplo: CV indicando problema de concordância verbal; $\mathrm{R}$, para problema de regência, etc.); d) a correção textual-interativa, caracterizada por recados, comentários que o professor deixa ao longo do texto do aluno, estabelecendo, assim, interlocução não codificada com este; nesses recados, o professor pode, por exemplo, discutir problemas de diferentes níveis do texto e, por vezes, apresentar solução ou sugestão para a tarefa de reescrita.

Na esteira da concepção de avaliação aqui assumida, não se pode admitir, conforme defendem Assis e Silva (2010), que apenas alguns tipos de correção sejam considerados interativos. Dito de outra forma, no quadro em que se concebe a tarefa de correção, aliada à ação de reescrita, toda e qualquer intervenção do professor no texto do aluno é de natureza interacional, dialógica. O que as diferencia, porém, é que uma pode ser mais autoritária, mais imprecisa ou mais provocadora que a outra". (ASSIS, 2016, p. 241-242)
} 
consegue resolver sozinho ou a partir de pistas (aqueles não propriamente linguísticos) versus o problema que o estudante não consegue resolver sozinho e que, por isso, é apontado de forma resolutiva pelo professor.

As assertivas apresentadas a seguir, construídas a partir dos pontos de vista que emergem nos discursos exemplificados, são tentativas de traduzir tais conflitos, marcados pela ação responsiva a outros discursos presentes no métier acadêmico, seja sobre a própria tarefa de avaliação de textos, seja sobre os objetos a ela relacionados: (i) seria melhor apresentar soluções prontas para os problemas assumidos como menores e apenas sugerir caminhos para aqueles tomados como mais implicados na essência do texto; (ii) os problemas que não são "propriamente de língua" precisariam ser superados pelo estudante de forma mais autônoma; (iii) os problemas ditos "de língua" são menores ou menos relevantes do que outros; (iv) os problemas tomados como linguísticos estão menos ligados à construção de uma imagem do autor. Penso que estas sejam questões que merecem reflexão por parte daqueles envolvidos na formação de estudantes universitários, na condição de pesquisadores ou não, orientadores ou não.

Outro ponto tematizado recorrentemente nas entrevistas é o limite acerca do quanto se pode interferir no texto do estudante, apresentando-Ihe ou não soluções prontas, como se evidencia no Quadro 5, a seguir:

Quadro 5 - Discurso dos professores nas entrevistas

4. j'aime bien euh coopérer avec euh l'écriture de l'étudiant... et je lui dit «voilà moi comment je dirais euh c'est à vous de voir vous choisissez ... si vous aimez bien ma formule vous pouvez la prendre "... voilà... donc... c'est une sorte de coopération qui qui corresponde à des sortes de solutions pour des problèmes parce que je veux que l'étudiant écrive le possible et donc euh ça ne me dérange pas de :: de de coopérer et de lui dire « vous pouvez prendre ma phrase vous pouvez prendre ma formule» [...] mais toujours en veillant à ce que l'étudiant ait le choix de ne pas la prendre.... parce que je veux qu'il se constitue comme auteur .... et qu'il sache prendre des décisions sur les formulations etcetera... (PF8)

5. quando o orientando se mostra mais autor... quer dizer... mais DO::no da voz... é outra coisa... aí eu quase não preciso mudar... é:: não preciso sugerir... a leitura nossa flui ... porque não há problemas graves de texto... (PB7)

Fonte: Dados da pesquisa.

No excerto (4), PF8 assume suas inserções no texto de seu estudante como algo positivo. Note-se que, no dito, há a visão da solução de redação do professor como um gesto de cooperação (j'aime bien euh coopérer avec euh l'écriture de l'étudiant... [..] c'est une sorte de coopération qui qui corresponde à des sortes de solutions pour des problèmes [eu gosto é:: de cooperar com é:: a escrita do estudante... [...] é uma espécie de cooperação que que corresponde a tipos de soluções para problemas]). No não dito, podemos flagrar uma espécie 
de contrapalavra a um discurso que condenaria essa ação (et donc euh ça ne me dérange pas de :: de de coopérer [...] mais toujours en veillant à ce que l'étudiant ait le choix de ne pas la prendre [e então é:: isso não me incomoda:: cooperar [...] mas sempre cuidando para que o estudante tenha a opção de não ficar com minha formulação]); noutros termos, algo que poderia indiciar o não consenso (ou a não aprovação) acerca dessa ação entre os pares.

A questão da autoria, em sua relação com a prática de avaliação dos textos, também é tematizada pelos entrevistados ( 9 dos professores o fazem), não necessariamente de forma uníssona. Como exemplo, vejamos novamente o Quadro 5. No excerto (4), a noção de autoria subjacente à consideração de PF6 parece estar diretamente associada à tomada de decisão por parte do escrevente no que toca às formas de dizer (parce que je veux qu'il se constitue comme auteur ... et qu'il sache prendre des décisions sur les formulations etcetera [porque eu quero que ele se constitua como autor ... e que ele saiba tomar decisões sobre as formulações etc.]). Já em (5), autoria, inicialmente associada ao fato de o estudante mostrar-se, no texto, "DO::no da voz" (o que poderia sugerir, por exemplo, algo relacionado a uma certa independência revelada na escrita ou, ainda, à construção de posicionamentos de vista apoiados coerentemente em princípios teóricos), parece se vincular também à qualidade do texto (porque não há problemas graves de texto), imagem que facilmente nos leva a evocar a questionável concepção de que um texto "que flui" é aquele que não tem problemas formais, que segue o padrão culto da língua.

A questão axial deste trabalho - a apropriação do discurso de outrem - é abordada por todos os professores entrevistados como um dos principais problemas dos textos dos estudantes do mestrado, com exceção de dois professores da França e um do Brasil. Com maior frequência, os professores remetem à falta de indicação de fonte e à apropriação indevida do discurso do autor consultado, o que poderia denunciar, sob o olhar do professor, falhas no processo de compreensão de conceitos e princípios por parte do estudante.

Resta-nos interrogar se e como as formas de apropriação do discurso de outrem e seus efeitos de sentido são abordados pelo professor no feedback escrito que ele emite ao estudante, quando do exame dos textos por ele produzidos no processo de formação. Veremos então quais respostas encontraremos na próxima secção.

Diálogos orientador/estudante na avaliação de textos acadêmicos: em cena, as relações com a palavra de outrem

A complexidade em torno da citação, seus papéis e efeitos de sentido trazidos ao texto, tal como apontei anteriormente em diálogo com Boch e Grossmann (2015), com frequência parece ser a motivação para intervenções dos professores na apreciação dos textos de seus orientandos. Poucas vezes, entretanto, nos dados examinados, essa complexidade é 
tematizada de forma explícita, conforme se mostrará a seguir, tomando-se os comentários dos professores inseridos nos textos por eles examinados.

Três eixos conduzirão minhas reflexões sobre os dados: (i) formas de introdução e diálogo com o discurso de outrem; (ii) aspectos epistemológicos e conceituais na apropriação do discurso de outrem; (iii) normas técnicas (e éticas) na tomada do discurso de outrem.

Guiando-me por uma perspectiva dialógica da linguagem (VOLÓCHINOV, 2017; BAKHTIN, 2003), cabe-me trazer ao leitor perguntas tomadas como uma orientação geral para a abordagem analítica dos dados. São elas: (i) As ações do professor na avaliação dos textos acadêmicos projetam como interlocutor um autor de texto acadêmico, negociando com ele parâmetros para a construção dessa identidade acadêmica (HYLAND, 2012), em um processo dialógico de instrução e colaboração? (ii) No retorno escrito ao autor do texto examinado, que posições-sujeito (em uma aproximação com Pêcheux (1975)) são assumidas pelo professor? Uma posição do pesquisador, experiente no fazer científico e na escrita científica? Uma posição de professor que avalia e ensina a forma correta de dizer no campo científico? Uma posição de um leitor da área que busca a compreensão do texto lido e pede respostas a seu autor? (iii) Que posições-sujeito são projetadas para o interlocutor (o autor do texto sob exame)? Alguém que não sabe as regras técnicas da escrita acadêmica? Alguém que desconhece as regras da norma padrão? Alguém que desconhece os efeitos sociais, institucionais e discursivos resultantes dos modos de dizer agenciados? (iv) Enfim, quais parâmetros, objetivos e valores parecem orientar o professor na tarefa de leitura/análise dos textos produzidos pelos seus alunos?

Os excertos a serem trazidos nos Quadros 6, 7 e 8 apresentam a seguinte organização: inserção do trecho do doutorando ou mestrando, em tipo normal, seguida do comentário do professor, sempre em negrito. Eventuais inserções do professor no texto do estudante também são destacadas com negrito.

Passemos ao primeiro excerto no Quadro 6:

Quadro 6-Feedback escrito dos professores aos orientandos

6. Selon Porcher, "Cette analyse des besoins est aujourd'hui trop souvent dévoyée, c'est-à-dire, transformée en une entreprise de verrouillage qui consiste à croire qu'on peut à coup sûr et une fois pour toutes repérer et fixer les besoins langagiers d'un public, puis en déduire un programme d'enseignement optimal qui répondrait totalement à ces besoins et seulement à eux. " (Porcher, 1978, p.9) (Artigo de doutorando)

Comentário de PF5: Il faudrait introduire cette citation, en disant qqe chose comme : "Cela dit, il ne faut pas imaginer couvrir tous les besoins langagiers : selon Porcher, en effet, " cette analyse.... "

Fonte: Dados da pesquisa. 
Como podemos ver, o que PF5 toma como problema é o modo como o discurso de outrem é apropriado pelo doutorando no artigo (II faudrait introduire cette citation, en disant qqe chose comme (...) [Seria preciso introduzir esta citação dizendo qualquer coisa como (...)]). Na sugestão de introdução da citação inserida por PF5 (Cela dit, il ne faut pas imaginer couvrir tous les besoins langagiers: selon Porcher, en effet, "cette analyse.... " [Dito isso, não é preciso pensar em cobrir todas as necessidades linguageiras: segundo Porcher, de fato, "essa análise..."]), parece restar implícita a indicação de que o escrevente observe a necessidade de construir diálogo com a citação, no qual se flagrem a pertinência da citação ao projeto de dizer do escrevente, bem como a manifestação de um ponto de vista sobre o dito (na citação). Noutros termos, subjaz à sugestão a ideia de que deveria haver uma espécie de "costura" cujos pontos usados no "texto-tecido" fossem capazes de garantir a sustentação da argumentação construída, de forma que o discurso citado não se mostre dominante em relação ao discurso do doutorando. No entanto, é preciso assinalar que não são tematizados, de forma explícita, os possíveis papéis do discurso de outrem na escrita acadêmica nem os prováveis efeitos de isso não ser observado pelo escrevente em seu texto. Dito de outro modo, a "dimensão funcional", o "poder de legitimação" e o "potencial produtivo" da citação, nos termos de Boch e Grossmann (2015), não são frontalmente abordados. Acrescente-se, ainda, que a ação do professor de sugerir uma solução para o problema pode ser interpretada como indicativa de que se projeta o escrevente na posição de alguém que não sabe, e por isso se apresenta a ele um caminho. ${ }^{20}$

Os dois recortes a seguir, no Quadro 7, trazem ocorrências - porém raras nos dados examinados - em que o comentário do professor parece fornecer ao estudante mais elementos para compreensão da restrição feita ao uso do discurso de outrem na escrita acadêmica.

Quadro 7 - Feedback escrito dos professores aos orientandos

7. Dans une approche psychanalytique, Jovenet A.M. (2015) a présente la notion de "l'intention » de l'enseignant, elle a cherché à discerner le rôle que joue l'intention de l'enseignant dans l'activité de transmission /construction de contenus. II s'agit d'une confrontation entre intentions cachées et intentions déclarées à l'intersection de la relation à l'élève et du rapport aux contenus. Dans la perspective de ma recherche, cette notion peut trouver place dans le " dire » des contenus, qui sera présenté dans la partie suivante, en reliant les effets de l'intention de l'enseignant sur sa manière de « dire » des contenus. Pour ce faire, la recherche sera étayée par des entretiens avec les enseignants concernés afin d'avoir leurs déclarations sur les contenus qu'ils avaient l'intention de transmettre et

20 Obviamente, estou considerando, no caso desse comentário examinado, bem como nos demais que são trazidos a este texto, que a interação professor/estudante no processo da escrita acadêmica não se restringe ao que está sendo por nós examinado, havendo, naturalmente, seja por meio de encontros presenciais, seja por meio de outros expedientes, possibilidades de que os aspectos apontados por nós como ausentes ou implícitos sejam tratados de outra forma. 
d'autres contenus qui pourraient surgir sans intention préalable. (Síntese de pesquisa, master 1)

Comentário de PF3: Ferez-vous usage de cette approche ? Si c'est le cas, comment ? Si ce n'est pas le cas, pourquoi la citer?

8. Selon Cortier (2007, p. ?), l'approche sociodidactique est :

« uUne didactique articulée à la variété des contextes dans leurs aspects politiques, institutionnels, socioculturels et sociolinguistiques d'une part, mais aussi à la variété et la variation langagière, linguistique et sociale, interlectale et interdialectale, d'autre part, et pour laquelle sociolinguistique scolaire et didactique du plurilinguisme sont deux champs qu'il est absolument nécessaire de convoquer concomitamment, pour l'élaboration de politiques linguistiques et éducatives cohérentes. » (Artigo de doutorando)

Comentário de PF5: Je ne suis pas sure que toute cette citation (qui est assez longue) vous soit utile : vous ne la commentez pas. A supprimer?

Fonte: Dados da pesquisa.

Nos dois casos trazidos no Quadro 7, há, nos comentários de PF3 e PF5, focalização explícita de uma função para o uso do discurso de outrem, que, ao que parece, deveria estar clara para o escrevente e para o leitor do texto. Atente-se, ainda, no caso do recorte 8, para uma observação sobre a extensão da citação - (qui est assez longue [que é bastante longa]) , que poderia ser interpretada pelo estudante como um segundo problema a ser corrigido e não necessariamente como algo diretamente implicado no não reconhecimento, pelo professor, de uma função para a citação tematizada.

A questão da extensão da citação aparece em comentários de outros cinco professores colaboradores da pesquisa, ${ }^{21}$ porém sem nenhuma pista explícita quanto à sua justificativa, de modo que a citação longa poderia ser interpretada pelo estudante como uma espécie de interdição em si mesma.

A esse respeito, lembro que, não raramente, pesquisadores seniores justificam ao leitor o uso de citações longas em seus textos. Como exemplo desse recurso, menciono o linguista Sírio Possenti, que, em sua importante obra Os limites do discurso: ensaios sobre discurso e sujeito, assim prepara o leitor duas extensas citações de Foucault a serem introduzidas em sequência:

Os leitores terão que suportar duas longas citações, o que certamente não é pior do que suportar longas repetições e paráfrases. Começo lendo uma passagem de um

\footnotetext{
${ }^{21}$ A título de ilustração: Você precisa mesmo de uma citação deste tamanho? (PB6); Não seria melhor retextualizar a citação? São quase 15 linhas aqui!!! (PB2).
} 
autor fundamental, em especial porque é notoriamente não-linguista e porque alguns de seus conceitos foram em parte transmutados para funcionarem como discurso: [...]. (POSSENTI, 2002, p. 28-29)

Como claramente pode ser percebido, há silêncios nessa justificativa do autor que podem ser facilmente escutados e, por isso mesmo, mereceriam ter lugar na discussão sobre o processo de apropriação da escrita acadêmica pelos estudantes.

Na quase totalidade dos textos examinados, flagram-se pistas de uma preocupação do professor - sobretudo, ao que parece, dada a sua posição de orientador - com a pertinência, do ponto de vista epistemológico ou apenas conceitual, da apropriação do discurso de outrem. Vejamos alguns excertos:

Quadro 8-Feedback escrito dos professores aos orientandos

\begin{abstract}
9. Ao considerar criticamente a força ilocutória dos atos de linguagem, Bourdieu (1982) nos remete a um poder exterior ancorado nos quadros institucionais e nos rituais sociais, opondo-se ao verbo. Para Bourdieu, uma ação como a exercida pelo orador sobre seu auditório não é de ordem linguageira, mas social, uma vez que essa ação depende da posição social desse orador e de suas "possibilidades de acesso à palavra oficial ortodoxa, legítima" e não da imagem de si que o locutor produz em seu discurso. (Capítulo de dissertação)
\end{abstract}

Commentaire de PB4: Acho que esse parágrafo ainda não está bem enquadrado, E. Os argumentos nele apresentados me parecem contraditórios ${ }^{22}$ em relação às concepções de Benveniste e Bakhtin, para os quais a dimensão social é 'constitutiva' das práticas discursivas, do processo de enunciação. 0 que acha disso?

10. Assim, os modos de ler remetem aos modos de usar o texto, isto é, às formas como cada leitor lê os diferentes tipos de texto. Nessa visão, aspectos sociais e históricos como características textuais (parágrafos, tipos de letras, títulos, entre outros), intenções do público, intenções de leitura e o nível de instrução do leitor podem determinar os modos de ler (Chartier, 2001; Bourdieu, 2001). (Capítulo de tese de doutorado)

Comentário de PB1: Toda essa passagem em amarelo remete diretamente a uma obra de Chartier, mas o modo como você apresenta não deixa transparecer isso. Ainda, sobre isso que vc afirma: "Nessa visão, aspectos sociais e históricos como características textuais (parágrafos, tipos de letras, títulos, entre outros)", parece-me que há um gap, isto é, você parece ter resumido e deixado de fora termos importantes relativamente às características textuais, creio que tais características são formais. Volte ao texto a que vc recorre.

\footnotetext{
${ }^{22}$ PB4 remete à discussão anterior do capítulo, em que é apresentada e justificada a filiação do texto à perspectiva enunciativa.
} 
11. L'idée saussurienne, selon Barthes (1966), définit la notion de langue, du point de vue du genre littéraire, comme une forme et non comme une substance. Cette pensée se réfère au concept du paradigme pouvant se transmettre aux multiples types de marques grammaticales. Ces traits grammaticaux sont par exemple: le genre, le temps, le mode, le nombre, la fonction syntaxique, la classe lexicale, etc. Il explique, en outre, que la langue est à la fois acquise et innée chez l'homme. En ce sens, ce linguiste va à l'encontre de la fonction culturelle définie par Texier (2004). Il montre en effet que si la langue n'est pas complètement naturelle, elle n'est pas non plus un produit de la culture en totalité car son système est inchangeable du fait de ses règles grammaticales.

Comentário de PF7: Vous mélangez trop de choses dans ce paragraphe. Le lecteur ne comprend pas. Ne pas remonter jusqu'à Barthes!! Voir une synthèse sur ces questions dans la pièce jointe sur l'acquisition extraite de Cuq et al.2002

Fonte: Dados da pesquisa.

O cuidado dos professores da pesquisa relativamente à dimensão teórico-conceitual, flagrado na grande maioria dos materiais cedidos para este estudo, pode ser medido tanto pela extensão dos comentários apresentados pelo professor quanto pela presença de argumentos, explicações e mesmo sugestões de leitura ao estudante.

Ainda que algumas das observações feitas pelos professores nos excertos ilustrados no Quadro 8 sejam construídas num tom que parece dar ao escrevente uma posição de autor - como se verifica, por exemplo, na formulação de perguntas ( $O$ que acha disso?) e na utilização de modalizações (Acho; você parece), que relativizam, de certa forma, a assimetria que caracteriza as posições sociais de estudante e de professor (orientando e orientador) e mesmo as posições que estes ocupam na comunidade acadêmica -, tais intervenções estão, na verdade, focalizando "fragilidades" da leitura do estudante, interpretações não autorizadas, não balizadas pelo campo disciplinar (Ne pas remonter jusqu'à Barthes !! [Não retornar até Barthes!!]). Nessa medida, tais inserções colocam em relevo, de alguma forma (ou, talvez, sobremaneira), o lugar, isto é, a posição que o estudante ocupa na comunidade discursiva, e não necessariamente os efeitos da apropriação de conceitos/noções/quadros teóricos na escrita de pesquisa.

Resta por fim assinalar, também na mesma direção revelada nos discursos dos professores nas entrevistas, a recorrência de intervenções sobre a apropriação do discurso de outrem fora dos padrões técnicos, por vezes também marcadas, de modo mais ou menos direto, como fora dos padrões éticos. Os feedbacks nessa direção, nos dados examinados, dividem-se entre (i) apenas instruções ao estudante para a correção do problema; (ii) questionamento ao estudante sobre a existência do problema, seguido de orientação para correção, a ser avaliada conforme o caso; (iii) explicitação do problema e repreensão do estudante, seguida ou não de orientação para a sua correção. 
Os três exemplos a seguir, no Quadro 9, ilustram, na sequência, as situações aludidas:

Quadro 9-Feedback escrito dos professores aos orientandos

12. OK, mais il faudrait citer l'auteur et la date pour appuyer cette idée. (PF5)

13. Qui parle, là ? Si c'est vous, citez vos sources d'inspiration (PF3)

14. S., NÃO É POSSÍVEL COPIAR QUASE QUE INTEIRAMENTE UM TRECHO DE UM ARTIGO SEM

CITÁ-LO. IMAGINE QUE TIVE QUE IR À INTERNET ACHAR O TEXTO. RECOMENDO QUE VOCÊ NÃO SE DESCUIDE TANTO ASSIM. É RUIM PARA VOCÊ E PARA O PROGRAMA. (VEJA O ARTIGO $\left.\left[{ }^{* 23}\right]\right)$. POR FAVOR, VEJA ESSE TIPO DE OCORRÊNCIA EM OUTROS MOMENTOS DO TRABALHO.) (PB2)

Fonte: Dados da pesquisa.

$\mathrm{Na}$ intervenção (12), o dito focaliza tão somente a instrução do professor para a correção de um problema; entretanto, ainda que silenciada, a existência do problema é pressuposta (mais il faudrait citer l'auteur et la date pour appuyer cette idée [mas seria preciso citar o autor e a data para apoiar essa ideia]) .

Em (13), a pergunta parece remeter a uma dúvida sobre a fonte do dizer (Qui parle, là ? [Quem fala aqui?]), embora a orientação seguinte (Si c'est vous, citez vos sources $d^{\prime}$ inspiration [Se é você, cite suas fontes de inspiração]) abrigue, ao mesmo tempo, como pressuposto, a existência de um problema e, como subentendido - pela natureza da orientação expressa -, a ideia de que o escrevente não estaria revelando ao leitor a real origem de seu dito. Em outros termos, embora se esteja, indiretamente, apontando a ocorrência de uma violação às normas da escrita acadêmica, isso parece ser amenizado, de certa forma, por meio da formulação da pergunta (Qui parle, là ?), bem como da oração condicional (Si c'est vous).

Já na intervenção (14), as falhas do trabalho de escrita são indicadas de maneira explícita e dura ao mestrando (chamo atenção para o uso das letras maiúsculas), em que prevalece um tom ameaçador e condenador, o qual alude, inclusive, a efeitos que poderão incidir até mesmo sobre a imagem do estudante (como pessoa física) e da instituição em que ele cursa o mestrado.

\section{Considerações finais}

Sabemos que o processo de apropriação da escrita acadêmica é longo, complexo e, frise-se, inevitavelmente permanente. Mesmo para pesquisadores experientes, a vivência da

${ }^{23}$ PB2 insere link de acesso ao artigo de onde um trecho teria sido copiado. 
escrita acadêmica não se dá sem obstáculos, os quais podem assumir variados matizes, conforme o nível de pressão (institucional, pessoal, não necessariamente desvinculados) que marque o processo de produção escrita.

Ainda que se admita a inevitabilidade de obstáculos (menores ou maiores) na/para a escrita acadêmica, estes também devem ser concebidos como relacionados ao processo de letramento acadêmico vivido nas instituições de ensino superior.

No que respeita à pesquisa apresentada neste texto, tenho clareza de que as relações dialógicas orientador/orientando não se restringem aos dados examinados, nem se limitam à modalidade escrita. Afinal são muitos os fatores, não necessariamente todos eles abordados, que concorrem para a variação nos modos como o professor retorna o resultado de sua leitura ao estudante.

Mesmo reconhecendo essa condição, avalio que não se pode perder de vista que os resultados da pesquisa aportam pistas significativas sobre esse processo, o que me faz defender a importância de se investigar o papel das ações dos professor nesse percurso, especificamente, quando ele se debruça sobre o texto do estudante. Afinal, é sempre por meio da interpelação do outro (projetada ou realizada) - seja o outro o par, o professor, a referência teórica que se admira - que a identidade acadêmica vai, enfim, se desenhar no texto.

Nesse sentido, parece-me essencial que os papéis da citação, os jogos que se criam por meio dela e os prováveis efeitos de sentido desses jogos na construção de uma identidade autoral acadêmica tenham centralidade na formação e, em razão disso, não sejam colocados à margem nos feedbacks do professor ao estudante.

\section{Referências}

ASSIS, J. A. Relações dialógicas no ensino da escrita: papéis e efeitos da correção de textos no processo de apropriação de gêneros do discurso. In: GUIMARÃES, A. M. de M.; BICALHO, D. C.; CARNIN, A. (Org.). Formação de professores e ensino de língua portuguesa. Campinas, SP: Mercado de Letras, 2016. p. 227-257.

ASSIS, J. A.; SILVA, J. Q. G. Processo de construção identitária na relação dialógica entre formador e formando, 2010. Disponível em: <http://www.ich.pucminas.br/posletras/13.pdf>. Acesso em: 20 jul. 2016.

BAKHTIN, M. M. Estética da criação verbal. Tradução de Paulo Bezerra. São Paulo: Martins Fontes, 2003.

BOCH, F.; GROSSMANN, F. Sobre o uso de citações no discurso teórico: de constatações a proposições didáticas. In: ASSIS, J. A.; BOCH, F.; RINCK, F. (Org.). Letramento e formação universitária: formar para a escrita e pela escrita. Campinas, SP: Mercado de Letras, 2015. p. 283-308. (Série Ideias sobre Linguagem). 
CASTILHO, A. T. de; PRETI, D. (Org.). A linguagem falada culta na cidade de São Paulo - Projeto NURC/SP: Diálogos entre dois informantes. São Paulo: T. A. Queiroz, 1987. v. 2.

HYLAND, K. Disciplinary identities: Individuality and community in academic discourse. New York; Cambridge: Cambridge University Press, 2012.

KLEIMAN, A. B.; ASSIS, J. A. (Org.). Significados e ressignificações do letramento: desdobramentos de uma perspectiva sociocultural da escrita. Campinas, SP: Mercado de Letras, 2016.

LEA, M. R.; STREET, B. V. O modelo de letramentos acadêmicos: teoria e aplicações. Trad. de Fabiana Komesu e Adriana Fischer. Filologia e Linguística Portuguesa, São Paulo, v. 16, n. 2, p. 477-493, 2014.

LUCKESI, C. C. Avaliação da aprendizagem na escola e a questão das representações sociais. EccoS Rev. Cient., UNINOVE, São Paulo, n. 2, v. 4, p. 79-88, 2002. https://doi.org/10.5585/eccos.v4i2.310

MAINGUENEAU, D. Novas tendências em análise do discurso. Trad. de Freda Indursky. Campinas, SP: Pontes, 1993.

PÊCHEUX, M. A Análise do Discurso: três épocas. Trad. de J. de A. Romualdo. In: GADET, F.; HAK, T. (Org.). Por uma Análise Automática do Discurso: uma introdução à obra de Michel Pêcheux. Campinas: Ed. da Unicamp, 1997. p. 311-320.

POSSENTI, S. Os limites do discurso: ensaios sobre discurso e sujeito. São Paulo: Parábola Editorial, 2009.

ROMÃO, J. E. Avaliação: exclusão ou inclusão? EccoS Rev. Cient., UNINOVE, São Paulo, n. 1, v. 4, p. 43-59, 2002. https://doi.org/10.5585/eccos.v4i1.292

RUIZ, E. M. S. D. Como se corrige redação na escola. Campinas, SP: Mercado de Letras, 2001.

SERAFINI, M. T. Como escrever textos. Trad. de Maria Augusta B. de Mattos. São Paulo: Globo, 1989.

STREET, B. V. Literacy in theory and practice. Cambridge: Cambridge University Press, 1984.

STREET, B. V. What's "new" in New Literacy Studies? Critical approaches to literacy in theory and practice. Current issues in comparative education, New York, v. 5, n. 2, p. 77-91, 2003.

VOLÓCHINOV, V. N. Marxismo e Filosofia da Linguagem: problemas fundamentais do método sociológico. Tradução, notas e glossário de Sheila Grillo e Ekaterina Vólvoka Américo. São Paulo: Editora 34, 2017. 